\title{
Introduction to editorial board members
}

\author{
Dr. Sujit Bhattacharya, Ph.D \\ Editor-in-Chief, Journal of Scientometric Research, Senior Principal Scientist (NISTADS) \\ Dr. K.S. Krishnan Marg, Pusa Campus, New Delhi-110012, INDIA
}

\section{Editor in Chief}

Sujit Bhattacharya is a Senior Principal Scientist in NISTADS, New Delhi and Editor-In-Chief of the 'Journal of Scientometric Research'. He received his

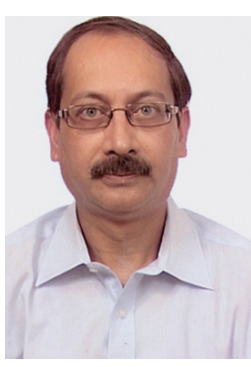

$\mathrm{PhD}$ from Indian Institute of Technology, Delhi (India) in Quantitative Sociology. He works in the area of 'Science, Technology and Innovation (STI) Policy Studies', Scientometrics, and Intellectual Property Rights. He has published widely in the aforesaid areas. He has led some key national projects and is actively involved in various capaci-

ties with the STI community. He had two year tenure as Professor at the Centre for Studies in Science Policy, Jawaharlal Nehru University where he was instrumental in introducing IPR and Scientometrics as areas of research and teaching. He is involved in introducing and incorporating scientometrics as a research area in India and developing countries, and engaging researchers from other disciplinary streams to explore and contribute to this field.

\section{Editors}

\section{Editor}

K.C. Garg is the former Chief Scientist of the National Institute of Science Technology and Development Studies (NISTADS), India. He has more than 30 years of research experience in the field of scientometrics

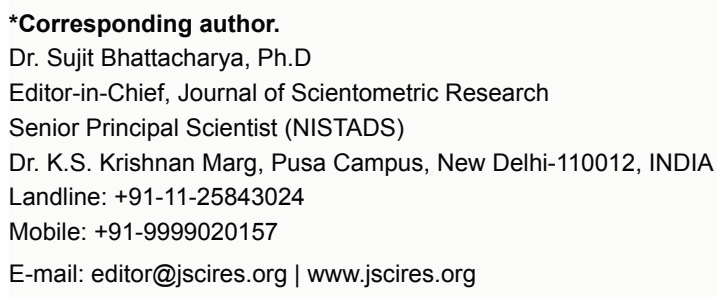

DOI: $10.5530 /$ jscires.2012.1.2 and informetrics. He is among the most prolific authors contributing in the journal Scientometrics. He has also

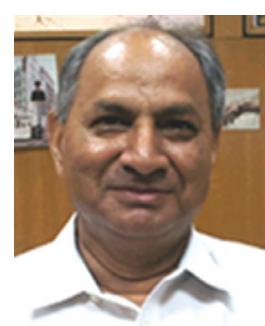
published widely in other international journals and in journals of developing countries. He has helped in the development of this field especially in India and other developing countries. He has led some important national projects and has been actively involved with different research groups in India and abroad.

\section{Editor}

Bart Thijs is with the Centre for R\&D Monitoring (ECOOM) of the Department of Managerial Economics, Strategy and Innovation (MSI) in K.U. Leuven, Belgium as a Senior Research

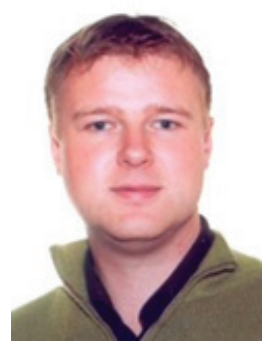
Faculty. He received Ph.D. from Leiden University, the Netherlands in Scientometrics.

He has been actively involved in research in different domains of scientometrics reflected in his prolific contributions. Actively involved in developing the research community through development of course modules, specialized workshops and teaching.

\section{Editor}

Divya Srivastava is at Indian Council of Medical Research, India as Senior Scientist. She is a doctorate in

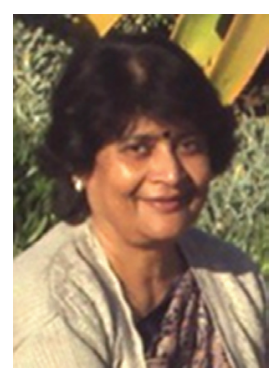
Botany and Master's in Information Science. She has more than thirty years of research experience in Scientometrics and Informetrics. She is Fellow of the Society for Information Science, India.

Her dedicated bibliometric research work to explore the dynamics of 
medical research in India and other countries has attracted attention of the medical community. Along with research papers, she has produced valuable bibliometric based research reports addressing pressing issues in science and technology in general and medical research in particular.

\section{Assistant Editors}

\section{Assistant Editor}

Jayanthi A. Pushkaran is a PhD Scholar at the Centre for Studies in Science Policy, Jawaharlal Nehru University.

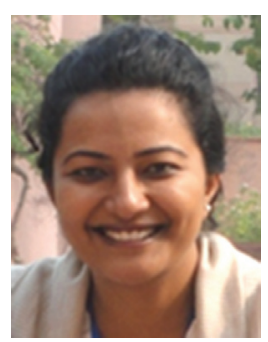

She is interested in social dimensions of research, social network analysis, and issues in emerging technologies and is contributing actively in these themes. She has expanded her horizon and now working actively towards incorporating hybrid indicators in understanding $\mathrm{S} \& \mathrm{~T}$ issues.

\section{Assistant Editor}

Anup Kumar Das is associated with Centre for Studies in Science Policy of Jawaharlal Nehru University, India as research staff. He received doctoral degree in

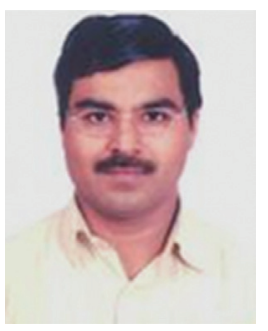
Information Science from Jadavpur University, India. He was associated with UNESCO New Delhi office during 2006 to 2009 as external consultant and subject expert in areas of information and communication. His research interests include open access, open science, webometrics, and social networking. He engages actively with national and international agencies in the above areas.

\section{Editorial Board Members}

Gangan Prathap is Director of CSIR-National Institute of Science Communication and Information Resources, India. Formerly he was Vice Chancellor, Cochin Univer-

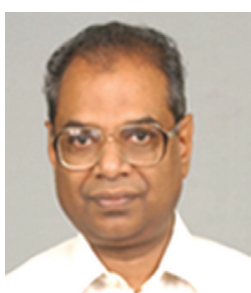
sity of Science \& Technology, India. $\mathrm{He}$ received his $\mathrm{PhD}$ in Aerospace Engineering from Indian Institute of Technology Madras, India in 1978. He was awarded the highest prize in Science and Technology in India the S.S. Bhatnagar Prize in 1990. He is the Fellow of the Indian Academy of Sciences and the Fellow of Indian National Science Academy, India.
He brings in scientometrics insights from his prolific contributions in engineering research particularly in nonlinear structural mechanics. His research work in scientometrics is leading to new perspectives and is attracting attention of researchers and policy community.

Martin Meyer is Professor in Business \& Innovation and Head of Business \& Management at the University of Sussex, UK. He received doctorate degree in Science

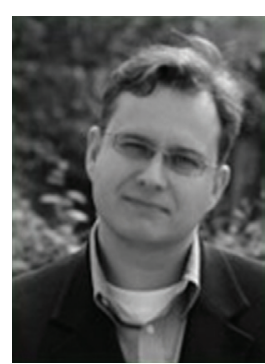
and Technology Policy Studies from SPRU, UK. He has been associated in various capacities with a large number of international academic institutions such as Helsinki University of Technology, K.U. Leuven.

He is among the most prolific contributors to the research field encompassing Science and Technology Studies, Innovation and Entrepreneurship. He combines bibliometrics with other approaches to provide novel insights in understanding knowledge exchange, academic patenting and emerging science-based technologies. A distinct feature of his research is collaborative linkages with researchers across the world. He has helped develop the research community through his active collaborative work, teaching and varied academic engagements.

Prajit Kumar Basu is with the Department of Philosophy, Hyderabad Central University, India as Professor in

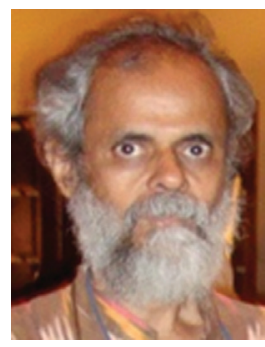

History and Philosophy of Science. $\mathrm{He}$ received doctorate degree in Technology from Indian Institute of Science, Bangalore and doctorate degree in Philosophy of Science from University of Iowa, USA.

He has played an influential role in attracting young scholars from diverse background in Science and Technology Studies (STS). His work reflects the rich crossfertilisation of ideas from different research traditions. He provides novel insights to the approach of quantitative methods including bibliometrics in STS studies.

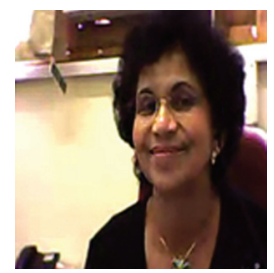

Daisy Jacobs is Professor at the Department of Information Studies, University of Zululand, South Africa. She is actively involved in developing Scientometrics as a research field in South Africa. Her activities range from teaching, guiding students at masters and $\mathrm{PhD}$ 
level, and engaging with the research community and government in various capacities. She was the General Chair of the International conference for the 2011 Scientometrics and Informetrics Conference in South Africa. This conference has helped to attract new scholars in scientometrics in Africa.

Parveen Arora is Director of the National Science \& Technology Management Information System (NSTMIS), Ministry of Science \& Technology, India. He

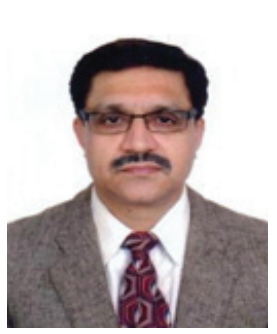
received $\mathrm{PhD}$ degree in Science Policy Studies from Jawaharlal Nehru University, India.

$\mathrm{He}$ is the national expert in science, technology and innovation (STI) indicators to UNESCO Institute of Statistics. His efforts have led to strengthening the innovation and S\&T monitoring system in India. He is closely associated with international bodies/member countries in constructing and developing guidelines and benchmark for STI indicators. His engagement in this field has led to better appreciation of bibliometric based research as policy input in India and other developing countries.

Farideh Osareh is Director and Professor at the Department of Library \& Information Science, Shahid Chamran University, Iran. She received $\mathrm{PhD}$ degree in Bibliometrics \& Scientometrics from New South Wales University, Australia. She was awarded distinguished woman researcher of Iran (one of the top seven women researches) in 2004. Her work has led to wide interest in this field in Iran and has motivated young scholars to work in this field. She is associated with the international research community in this field in various capacities.

B. M. Gupta is the former Chief Scientist of the National Institute of Science Technology and Development Studies (NISTADS), India and currently emeritus scientist of NISTADS. He is the recipient of the

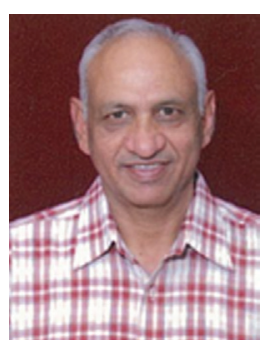

Fullbright Professional Fellowship in Library \& Information Science (1999) and is the fellow of the Society for Information Science. He has more than forty years of research experience in the field of Scientometrics. He is among the most prolific contributors globally in this field. His work has explored research dynamics globally in different areas with particular reference to India and developing countries.
Grant Lewison worked at the Wellcome Trust as Senior Policy Advisor from 1993-2003 and was Visiting Professor at City University before setting up his own company Evaluametrics Ltd, United

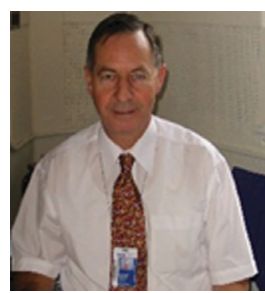
Kingdom, which undertakes research evaluation through publication metrics. He is also a Senior Research Fellow at University College, London.

He has carried out many consultancy assignments in bibliometrics and written about 70 papers. He is among the most influential scholars in this field and is on the editorial boards of the journals Research Evaluation and Scientometrics. He actively collaborates with researchers across the world and has been instrumental in sensitising the policy community in UK and other countries. His current activities are mostly focussed on biomedical research outputs and their evaluation by means of multiple indicators, including citation in the mass media, on clinical guidelines and on government policy documents.

Jacqueline Leta is a $\mathrm{PhD}$ in Management, Education and Diffusion in Biosciences from Federal University of Rio de Janeiro (UFRJ). She is presently Associate Professor of Med-

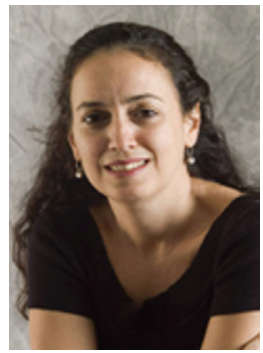
ical Biochemistry Institute at UFRJ.

Her major areas of research focus are in the field of informetrics, with emphasis on the analysis of Brazilian scientific production, focusing on issues related to health sciences and women in science. She has actively contributed to the development of this field. Involved in important committees in the Brazilian Ministry of Science \& Technology overseeing the development of this area. Organized In 2009 the International Conference on Scientometrics and Informetrics in Rio de Janeiro. She is the author of a book, book chapters and dozens of papers on Brazilian science. Has conducted a post-doctorate at the Catholic University of Leuven, in Belgium (2005).

\section{Editorial Advisors}

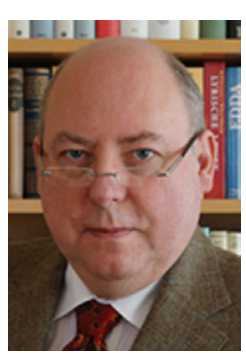

Wolfgang Glänzel is Director of Centre for R\&D Monitoring (ECOOM) of the Flemish government and Professor at K.U. Leuven, Belgium. He is also affiliated with the Department of Science Policy \& Scientometrics at the Library of the Hungarian Academy of Sciences. He holds doctorate in Mathematics 
from the Eötvös University in Budapest (1984) and a PhD in Science Studies from Leiden University (1997). In the 1990s he spent two years in Germany as Research Fellow of the Alexander von Humboldt Foundation. He is the Secretary-Treasurer of the International Society for Scientometrics and Informetrics (ISSI). He was awarded the Derek de Solla Price Medal "for outstanding contributions to quantitative studies of science" in 1999.

Wolfgang Glänzel is Co-Editor of the international journal Scientometrics.

Ronald N Kostoff is a Ph.D. in Aerospace and Mechanical Sciences from Princeton University (USA). He was for many years Director of the Office of Technical Assessment at the U.S. Navy Office of Naval Research. Presently he is a Research Affiliate with the School of Public Policy of the Georgia Institute of Technology (USA).

He has played a seminal role in the introduction of quantitative evaluation techniques in S\&T strategic management. He is one of the most prolific researchers in this area. Among his influential contributions is the development of textual data mining techniques. He is listed in Who's Who in America, Who's Who in Science and Engineering, and 2000 Outstanding Intellectuals of the 21 st century.

Ronald Rousseau is presently an Associate Professor at KHBO (Catholic School for Higher Education BrugesOstend), Department Industrial Sciences and Technology, Belgium and Professor to the K.U. Leuven, Belgium. He

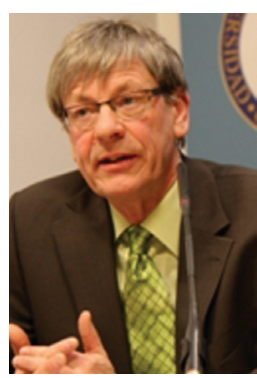
received doctorate degree in mathematics from University of Leuven in 1977 and doctorate degree in library and information science from University of Antwerp, Belgium in 1992. He is the President of the International Society for Scientometrics and Informetrics (ISSI) since 2007. He was awarded the Derek de Solla Price Medal "for outstanding contributions to quantitative studies of science" in 2001. He was awarded Prize of the Belgian Academy of Science in 1979, NATO scholarship in 1981 and Fulbright/Hays scholarship in 1981.
He is among the most influential scholars in Scientometrics. His contributions are in different domains of this field, opening new avenues of research as well. He has played a key role in attracting young researchers from all over the world to this field.

Ashok Jain is the former Director of CSIR-National Institute of Science Technology and Development Studies (NISTADS), India and the Honorary Vice President (Research \& Academic Devel-

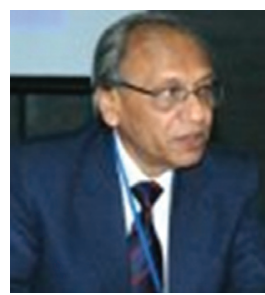
opment) of EMPI Business School, India. He is the Fellow of National Academy of Sciences, India and President of Society for the Promotion of S\&T Studies, India. He has more than forty years of research experience in the field of S\&T Studies (STS). He has widely contributed in the different domains of this field and is instrumental in making this a core area of research in India. He is playing a seminal role in influencing the scientists and researchers to the potentiality and applicability of S\&T indicators. His efforts have led to wider appreciation and incorporation of $S \& T$ indicators in assessing the S\&T system and decision making in India and in many developing countries.

Mu Rongping received his Ph.D. degree from Technische Universität Berlin, Germany. He is the director-general and professor of Institute of Policy and Management (IPM), Chinese Academy of Sciences (CAS), director-general of the CAS Center for Innovation and Development, editorin-Chief of the Journal of Science Research Management. Besides, he is Vice President and Secretary-General of the China High-tech Industry Promotion Society (CHIPS), Vice President of the Chinese Association for Science of Science and S\&T Policy Research.

He has published widely in peerreviewed journals, and has led more than 20 research projects of national and international bodies. His research interests include S\&T \& Innovation Policy, Technology Foresight, R\&D Management, and Competitiveness of High-Tech industry. 